\title{
Causality between Exchange Rates and Stock Prices: Evidence from Malaysia and Thailand
}

\author{
Ai-Yee Ooi (Corresponding author) \\ School of International Business and Finance Labuan \\ Universiti Malaysia Sabah \\ 11700 Jalan Sg. Pagar, Labuan F.T, Malaysia \\ Tel: 60-87-466713 E-mail: ooiaiyee@yahoo.co.uk \\ Syed Azizi Wafa Syed Khalid Wafa \\ School of International Business and Finance Labuan \\ Universiti Malaysia Sabah \\ 11700 Jalan Sg. Pagar, Labuan F.T, Malaysia \\ Tel: 60-87-460473Ｅ-mail: sazizi@ums.edu.my

$$
\text { Nelson Lajuni }
$$ \\ School of International Business and Finance Labuan \\ Universiti Malaysia Sabah \\ 11700 Jalan Sg. Pagar, Labuan F.T, Malaysia \\ Tel: 60-87-460481_E-mail: nlajuni1978@yahoo.com \\ Mohd Fahmi Ghazali \\ School of International Business and Finance Labuan \\ Universiti Malaysia Sabah \\ 11700 Jalan Sg. Pagar, Labuan F.T, Malaysia \\ Tel: 60-87-466715 E-mail: mohdfahmi_ghazali@yahoo.com
}

\begin{abstract}
This study analyses the causal relationship between exchange rates and stock prices for Thailand and Malaysia. By using daily data from 1993 to 2003, this study attempts to examine the relationship between exchange rates and stock prices in Thailand and Malaysia during pre and post financial crisis. The paper also investigates the long-run relationship between the above-mentioned variables using Johansen-Juselius (1990) cointegration test and short-run dynamic causal relationship by using Toda-Yamamoto (1995) procedure. Likewise, variance decompositions (VDCs) analysis is employed to improve the predictable portion of exchange rate (stock price) changes on the forecast error variance in stock prices (exchange rates). Data from Thailand demonstrates the results predicted by the portfolio balance approach: stock prices lead exchange rates in both pre-crisis and post-crisis periods; however, Malaysian findings support portfolio approach in post-crisis.
\end{abstract}

Keywords: Exchange rates, Stock prices, Johansen-Juselius cointegration test, Granger-causality test, Toda-Yamamoto's procedure, VDCs, Thailand, Malaysia 


\section{Introduction}

In the early 1990's, Asian Economy greatly attracted international fund managers or lenders to invest their capital in Asian markets. Unfortunately, the crash in Thailand's financial system in 1997 caused sheer panic and huge capital outflow from the Asian region leading to the Asian Currency crisis. The Asian crisis proper began in Thailand in July 1997. From 1996-1997, the property and stock market bubbles in Thailand burst. At the same time, the exchange rates in Asian countries also experienced a drastic fall. The collapse of stock prices and exchange rates spread widely to all the Asian countries. However, in Malaysia and the Philippines, generally regarded as having escaped lightly, the decline in exchange rates were not worse than Thailand and South Korea. Adding the fall in stock market to the fall in the exchange rates to get a broader measure impact, Malaysia was put as the worst group of affected countries, with the Philippines just behind. In short, the conventional understanding that only South Korea, Thailand, and Indonesia were badly affected is not actually true by these measures. In actual fact, Malaysia and the Philippines were hurt almost as much. Even Japan, Hong Kong and Singapore suffered badly from the substantial hits.

Many researchers argue that the crisis had brought about a contagious effect, that is when a country's currency falls; the neighboring countries' currency would fall too. Edwards (2002) stated that "contagion reflects a situation where the effect of an external shock is larger than what was expected by experts and analysts". Therefore, it indicates that contagious effects are entirely different from normal transmissions of shocks across countries. When the Thai currency depreciated, commodities in Thailand would be cheaper than in Malaysia. Consequently, Malaysia would devalue its ringgit in order to compete with Thailand. When speculators had the opportunities, they short sell the ringgit (Mohamad, 2000) and this eventually deteriorated the East Asian economy.

On another viewpoint, some other researchers such as Mishkin (2000) have proposed that the actual cause of the Asian financial crisis lies right in the inherent structural weaknesses of the debt markets of the affected countries themselves. It was observed that many large Asian corporations were financing their investments and projects primarily from bank loans, and hence, were highly geared from their large debt to capital ratios. Though this strategy of high gearing allows them to invest much more as compared to relying on pure equity alone, it is also these very high levels of debt themselves that create vulnerability to negative macroeconomic shocks such as drops in aggregate demand, rising interest rates, or even currency devaluation, which all ultimately caused reduced cash flows that worsened the crisis.

Instead of hunting for the cause of the crisis, this study will focus mainly on finding the direction of interdependence between exchange rates and stock prices in Malaysia as well as in Thailand, with the hope that our empirical findings can give some information to the policy makers. Many researchers study the causal relationship between exchange rates and stock prices. In particular, Abdalla and Murinde (1997) examined the exchange rate-stock price relationship in India, Korea, Pakistan and Philippines. The studies conclude that there is unidirectional causality from exchange rate to stock returns. The findings of this relationship in foreign exchange and stock exchange markets lend great significance in policy matters. Pan et al. (2000) found that the daily exchange rate Granger-cause daily stock price based on the data from seven East Asian countries namely Hong Kong, Japan, Korea, Malaysia, Singapore, Taiwan and Thailand. They report that the impact is even stronger after the Asian currency Crisis. Wu (2001) employed cointegration analysis to provide evidence that Singapore currency's appreciation against the US dollar and Malaysia ringgit and depreciation against the Japanese yen and Indonesian rupiah have positive long-run effects on stock prices.

This paper differs from other studies: here we examine the impact between Malaysia and Thailand only by using the two currencies (MYR and THB) converts alternatively (numerator and denominator) for foreign exchange rate. The purpose in using only MYR and THB for foreign exchange rates is to examine the direct shock from either Malaysia or Thailand. From this method, we can determine and prove that there is bidirectional causal relationship between Malaysia and Thailand foreign exchange rates. Malaysia and Thailand are located near to each other and are within the Southeast Asia region. In addition, Malaysia shares some partnerships with Thailand in the political, economic and business sectors. These are the reasons that this study only examines MYR and THB for foreign exchange rates. We also conduct an in-depth study on how the exchange rate of both countries is related to the stock prices (vice versa). If the exchange rate market is found to lead the corresponding stock market, then the government should control the exchange rate in its government policy. In addition, the main concern of domestic economic policy is to stabilize stock market when there is a lead of stock market to exchange market.

Figure 1 shows the Thailand Stock Prices (SETI) fluctuations from 1 November 1993 to 31 August 2003. There was a big decline from 1996 to 1998 due to the Asian crisis. After the crisis, fluctuations in stock prices seem to be stable. In Thailand stock prices exhibit a decreasing pattern until 1998 but exhibit an increasing trend after that. Malaysian stock prices also faced the same problem between 1997 and 1998 but became more stable after 1998 (Figure 2). In the pre-crisis period, prices exhibit an increasing trend; however, during the crisis period they exhibit a decreasing pattern. After the crisis the prices continue to exhibit an increasing trend.

From the Figure 3, we can see that Thailand exchange rate is stably fluctuated from 1993 until 1996 and 1999 until 2003. The exchange rate is Thai baht per Malaysia ringgit. Between the periods 1996 to 1998, the trend seems to be 
aggressively increasing and decreasing. In Figure 4, Malaysia exchange rate also has the same condition. The Malaysian exchange rate is per Thai baht. The graph shows that there is an increasing trend before 1997 and after 1998. During 1997 until 1998 the exchange rate fluctuated upward and downward aggressively.

This study attempts to broaden the existing literature on the relationship between exchange rates and stock prices in Malaysia and Thailand during the 1997 currency crisis. Moving from the previous study, this research employs the combinations of (MYR/THB) for Malaysia and the (THB/MYR) for Thailand, both based on daily spot exchange rates. The purpose of using two different currencies (MYR and THB) between two countries (Malaysia and Thailand) is to examine whether these two different currencies will affect the relationship between stock prices and exchange rates in and between the two countries. More specifically, this study aims to investigate the relationship between exchange rates and stock prices in Malaysia and Thailand in the long run by employing Johansen's multivariate cointegration test, as well as to study the dynamic causal relationship between these two variables and to examine the momentum of adjustment in this causal relationship through variance decompositions.

\section{Literature review}

Prior to the Asian financial crisis, numerous studies have been carried out on the relationship between stock prices and exchange rate for a range of countries, both developed countries and developing countries. The empirical research of causal linkages between stock prices and exchange rates is still received special attention from many researchers, market regulators and policy-makers because of its relevant for policy implications. In fact, investors, who deal directly with the stock market and currently face integrated financial markets, are interested in the interaction between the involved variables that can be profitably exploited.

Among the example studies include the works by Abdalla and Murinde(1997), Granger, Huang and Yang (2000), Gunduz and Hatemi-J (2002), and Hatemi-J and Irandoust (2002). Most of the studies used Granger causal relationship between the two markets and the results show that traditional and portfolio approaches have supportive evidences. Abdalla and Murinde (1997) indicated that exchange rates lead stock prices in India, Korea, Pakistan and the Philippines. Hatemi-J and Irandoust (2002) found that changes in stock markets lead exchange rates which support the portfolio approach. Baharumshah et al. (2002) suggested that the stock market is an important determinant of exchange rate. However, Bahami-Oskooee and Sohrabian (1992) and Canova and De Nicolo (2000), failed to show any common trends between the exchange rate and the stock market. In another study, Granger, Huang and Yang (2000) investigated East Asian countries using recent Asian flu data, came to a conclusion that in South Korea the exchange rate changes lead stock markets while in the Philippines the opposite relation is found. They also found that data from Hong Kong, Malaysia, Singapore, Thailand and Taiwan indicate feedback relations, whereas those of Indonesia and Japan fail to reveal any recognizable pattern. Nieh and Lee (2001) indicated that there is no long-run significant relationship between stock prices and exchange rates in the G-7 countries and short-run significant relationship has only been found for one day in certain G-7 countries.

Bahmani-Oskooee and Sohrabian (1992) and Granger et al. (2000) stress the importance of the portfolio approach to analyzing the relationship between stock prices and exchange rates. This suggests that a rise in stock prices increases the domestic wealth of investors, facilitating a rise in the demand for money. Following the consequent rise in interest rates, capital is attracted into the domestic economy appreciating the domestic currency. This approach assumes there is a negative relationship between stock prices and exchange rates, with causality running from the stock market to the foreign exchange market. Given the speed with which international financial markets interact, the relationship implied by the portfolio approach should occur almost instantaneously. This explanation is the most relevant to this relationship during a currency crisis. Kasman (2003) indicated that stock indices of ISE and exchange rates move together in the long-run.

The asset market approach, at other extreme, indicates no relationship at all between exchange rate and stock prices as it treats exchange rate as an essential part of the price of an asset in terms of foreign currency. The major factors that change current exchange rate may not be the same for future exchange rate movements (i.e., currently exchange rate movement may be affected by export performance of a country, but in some future year exchange rate may be affected by some sudden supply shock, political events, productivity loss, war, stock market crash, hyper inflation or by other policy variables). Thus there should not be any causal relationship between these two variables (Muhammad and Rasheed, 2003). In the study by Kaminsky et al. (1998), stock prices are found to be the fourth best predictor of currency crises, of the variables used and the fourth best in terms of the persistence of the signal. In addition stock prices have an average lead-time of 14 months in advance of the currency crisis, measured from when the first signal occurs.

In retrospect of the literature, a number of hypotheses support the existence of a causal relation between stock prices and exchange rates. For instance, 'goods market approaches', Dornbusch and Fischer (1980) suggested that changes in exchange rates affect the competitiveness of a firm as fluctuations in exchange rate affects the value of the earnings and cost of its funds as many companies borrow in foreign currencies to fund their operations and hence its stock price. Ma 
and Kao (1990) found that a currency appreciation negatively affects the domestic stock market for an export-dominant country and positively affects the domestic stock market for an import-dominant country, which seems to be consistent with the goods market. Ajayi and Mongoue (1996) findings provided evidence to indicate uni-directional causality between the stock and currency markets in all the advanced economies while no consistent causal relations are observed in the emerging economies. The overall results for daily data provide evidence that the stock and currency markets are well integrated in the six advanced economies with the exchange rates responding to innovations in the stock markets.

\section{Theoretical framework}

The theoretical explanations on whether exchange rates Granger-cause the stock prices or vice versa have been attempted through traditional and portfolio approaches. According to the traditional approach, changes in exchange rate lead changes in stock prices and vice versa for the latter. From the view of traditional approach, the appreciation (depreciation) of local currency increase (decrease) indebtedness in foreign currency and increase (decrease) in production cost, particularly in developing economies. Developing economies means that the country's production is relying greatly on imported raw materials. A simple explanation is that appreciation (depreciation) of the exchange rates affects the performance of firms on domestic as sell as international markets, and this is turn affects the share price of the firm (Aggarwal, 1981).

Portfolio balance approaches stress on the role of capital account transaction. Exchange rates are determined by market mechanism as like all commodities. In the portfolio approach, rising (failing) of the stock prices would attract capital flows from foreign investors which may cause an increase in the demand for a country's currency. A rise (fall) in stock prices will lead to an appreciation (depreciation) in exchange rates due to an increase in the demand (supply) of local currency. In other words, an exogenous increase in domestic stock prices will create an increase in domestic wealth and this, in turn, will result in an increase in the demand for money, thus an increase in interest rates. High interest rates will cause capital inflows resulting in an appreciation of the domestic currency (Krueger, 1983).

\section{Data and methodology}

\subsection{Data}

The daily data for exchange rates and stock prices are retrieved from DataStream, covering the sample period from November 1, 1993 to August 31, 2003. The end-of-day stock indices used in this study covers the Bangkok S.E.T. Index for Thailand and the Kuala Lumpur Composite Index for Malaysia. The exchange rates data are end-of-period nominal exchange rates, and consists of MYR/THB and THB/MYR exchange rates. All the series are transformed into natural logarithm form. To examine the impact of Asian financial crisis on the relationship of the variables on these two countries, sample period that is divided into two sub periods that covers from 1 November 1993 to 31 May 1997 (pre-crisis) and 1 February 1998 to 31 August 2003 (post-crisis).

\subsection{Unit root test}

Due to the importance of stationary properties, Augmented Dickey-Fuller (ADF) test, and Phillips-Perron (PP) test are employed to examine for unit roots and evaluate the robustness of the integration properties of exchange rates and stock prices. We first tested for stationary and the order of integration of the variables, at levels as well as first differences. More specifically, we tested whether SP and EX are integrated of order zero, I(0), that is, whether they are stationary. This was achieved by performing the ADF test, based on a standard regression with ${ }_{k}$ constant and a time trend as follows:

$$
\Delta Y_{t}=\alpha_{0}+\alpha_{1} T+\alpha_{2} Y_{t-1}+\sum_{i=1}^{\kappa} \lambda_{i} \Delta Y_{t-i}+\varepsilon_{t}
$$

where $\alpha_{2}=p-1, \quad \Delta=$ the first difference operator, $T=$ time trend and $\varepsilon_{t}=\underline{i}=1$ white noise error. The lag length $k$ is selected based on Akaike Information Criterion (AIC) so that all the residuals $\varepsilon_{t}$ is white noise. The null hypothesis is that $Y_{t}$ has unit root (non-stationary), that is $\mathrm{H}_{0}: \alpha_{2}=0$, verses the alternative hypothesis that $Y_{t}$ is stationary or $\mathrm{H}_{1}: \alpha_{2}<0$. The test is done by Mackinnon (1996) test statistic at the $1 \%$ and $5 \%$ significant levels.

\subsection{Johansen's approach for cointegration}

After that, we proceed to test the cointegration between the two variables by using the maximum-likelihood approach of Johansen and Juselius (1990). This technique is appropriate for investigating the number of cointegrating relations among the variables involved. It is good practice to pretest all variables to assess their order of integration. In most instances the variables are integrated of the same order. The results of the test can be quite sensitive to the lag length. The most common procedure is to estimate a vector autoregression using the indifference data. Then use the same lag-length tests as in a traditional VAR. Estimate the model and determine the rank of $\pi$. The Johansen-Juselius technique (see Johansen (1988); Johansen and Juselius (1990)), here after referred to as the JJ technique which is a multivariate extension and allows for more than one cointegrating vector or common stochastic trend to be present in the data. Masih and Masih (2002) also summarise several advantages of JJ approach in testing for cointegration: (i) the JJ procedure does not prior assume the existence of at most a single cointegrating relationships; (ii) the JJ method is established on a unified framework for estimating and testing cointegration relations within the VECM formulation; (iii) JJ provide the appropriate statistics and 
the points distributions to test hypothesis for the number of cointegrating vectors and test of restrictions upon the coefficients of the vectors.

The Johansen (1991) model can be written jn error-correction form, as follow:

$$
\Delta Y_{t}=\delta+\sum_{t=1}^{k-1} \Gamma_{1} \Delta Y_{t-1}+\Pi Y_{t-k}+u_{t}
$$

where $Y_{t}$ is a column vector of the $\mathrm{n}$ variables, $\Gamma$ and $\Pi$ represent the coefficient matrices, $\Delta$ is a difference operator, and $\delta$ is the constant. If $\Pi$ has zero rank, then there is no linear combination that is stationary between the variables. However, if $\Pi$ is of rank $r>0$, there are $r$ possible linear combinations. $\Pi$ can then be decomposed in to two matrices, $\alpha$ and $\beta$, that is $\Pi=\alpha \beta^{\prime}$. In this representation, $\beta$ contains the coefficients of the $\mathrm{r}$ cointegrating vectors that render $\beta^{\prime} Y_{t}$ stationary, even though $Y_{t}$ is non-stationary, and $\alpha$ contains the speed adjustment coefficients. Before performing the $\mathrm{JJ}$ approach, the model has to be specified with regard to the inclusion of a constant or a trend, and the number of lags. It is unlikely that a time trend would be necessary for most financial markets, however, since there is some trend in the data (see Figure 1 to 4 ), a constant is included. The Akaike Information Criterion (AIC) is used to determine the number of lags for each series. Given that stock price and exchange rate tend up-downward over time, a linear deterministic trend is assumed for the tests.

\subsection{Causality test}

To test the causality between stock prices and exchange rates, Toda and Yamamoto (1995) procedure is used. The Toda and Yamamoto (1995) procedure essentially suggests the determination of the d-max, i.e., the maximal order of integration of the series in the model we suspect might occur in the process, and to intentionally over-fit the causality test underlying model with additional d-max lags. So that the VAR order is now $\mathrm{p}=\mathrm{k}+\mathrm{d}-\mathrm{max}$, where $\mathrm{k}$ is the optimal lag order. The coefficient matrices of the last d-max lagged vectors in the model are ignores (since these are regarded as zeros), and we can test linear or nonlinear restrictions on the first $\mathrm{k}$ coefficient matrices using the standard asymptotic theory.

\subsection{Variance decompositions (VDCs)}

This study has employed the variance decompositions (VDCs) approach as analytical tool. VDCs analysis is named as out-of-sample causality test, which used to provide an indication of the dynamic properties of the system. VDCs analysis is a convenient method to partition the variance of forecast error of a certain variable into proportions attributable to innovations or shocks in each variable in the system. A vector autoregression (VAR) can be written as a vector moving average (VMA). Where, equation (3) can be iterated backward infinite times to obtain equation (4).

$$
\begin{aligned}
& \Delta \mathrm{Y}_{\mathrm{t}}=\alpha_{0}+\sum_{\mathrm{i}=1}^{\mathrm{k}} \alpha_{\mathrm{i}} \Delta \mathrm{X}_{\mathrm{t}-\mathrm{i}}+\varepsilon_{1 \mathrm{t}} \\
& \Delta \mathrm{Y}_{\mathrm{t}}=\mu_{0}+\sum_{\mathrm{j}=0}^{\infty} \alpha_{1}^{\mathrm{j}} \varepsilon \mathrm{t}-\mathrm{j}
\end{aligned}
$$

where $\mu=\left(\mathrm{i}+\alpha_{1}+\alpha_{2}+\ldots \ldots\right)$. $\alpha_{0}$ is the unconditional mean of $\mathrm{X}_{\mathrm{t}}$. The fact in equation (4) is the VMA representation of Equation (3) in that variables (Yit) are expressed in terms of the current and past values of the various types of shocks ( $\varepsilon_{i t}$ ). The VMA representation of equation (3) is an essential feature of Sims (1980) methodology which allows a tracing out of the time path of the various shocks on the variables contained in the VAR system.

\section{Empirical results}

\subsection{Unit root test}

The Augmented Dickey-Fuller (ADF) and Phillips-Perron (PP) unit root tests results are presented in Table 1 and Table 2 respectively. Both of the test shows that all variables are stationary at first difference at $1 \%$ significance level. The ADF and PP test statistics are able to reject the null hypothesis at $1 \%$ significance level for all series in first-difference form. Putting all these results into perspective, all the variables are integrated of order one or I(1), and allow us to proceed with the cointegration tests.

\subsection{Johansen-Juselius's approach for cointegration}

Refer to Table 3, the results suggest the presence of cointegration among the variables in both sample periods. Evidence from both trace and maximal eigenvalue test suggests that there is at most a single cointegrating vector in pre-crisis. The null hypothesis is rejected for pre-crisis period where the t-statistic for trace and maximal eigenvalue are 95.5163 and 79.2681 respectively which means statistically significant at $1 \%$ level. As for post-crisis period, trace test suggest that there is an evidence of at most two contegrating vectors as the null hypothesis is rejected. The t-statistic is 32.4798 and it 
is statistically significant at $5 \%$ level. Meanwhile maximal eigenvalue suggest that there is at most one cointegrating vector with t-statistic of 18.6578 . Thus, it is statistically significant at $1 \%$ level. There are at most two cointegrating vectors or three stochastic trends in the data in post-crisis period. The findings demonstrated the existence of long run relationships among the variables. Although cointegration exists among the variables, not all of them will enter the cointegrating vector system. An important implication from these integration and cointegration tests is that the dynamic interactions among these variables need to be based on vector error correction modeling (VECM). Alternatively, the finding of cointegration among the variables validates the standard VAR in levels.

\subsection{Causality test}

The results of tests of restrictions from a VAR estimated by the procedure prescribed by Toda and Yamamoto (1995) are summarized in Table 4.

For the period of pre-crisis, the results demonstrate that exchange rate does not cause stock price and stock price also does not cause exchange rate in Malaysia at $10 \%$ significance level. This implies that there is no causality running from stock price to exchange rate and vice versa in pre-crisis. The finding is in contrast with Granger et al. (2000) and Pan et al. (2000). In Thailand, the results show that exchange rate does not cause stock price whereas stock price is found to lead exchange rate at $10 \%$ level. This indicates that there is unidirectional causality relationship between stock price and exchange rate. Thus, Thailand case supports the portfolio approach in pre-crisis. Results for the post-crisis, however, provide somewhat of a different story. There is unidirectional causality from stock price to exchange rate in Malaysia at $5 \%$ significance level. Therefore, Malaysia also supports the portfolio approach in post-crisis.

The findings for the relationship between stock prices and exchange rates across countries are showed in the same table. The results suggest that there is unidirectional causality relationship between Thailand stock price and Malaysia exchange rate in pre-crisis as its F-statistic is significant at 5\% significance level. No causal relationship between Malaysia stock price and Thailand exchange rate is found. For post-crisis period, there are unidirectional causality relationships between Thailand stock price and Malaysia exchange rate; Malaysia stock price and Thailand exchange rate in post-crisis. Both results are significant at $1 \%$ and $5 \%$ significance levels respectively.

The results for stock prices relationships across countries demonstrate that there is significant bidirectional causality between the stock prices of Malaysia (KLCI) and Thailand (SETI) at 5\% level in pre-crisis. Nevertheless, unidirectional causal relationship from Malaysia stock price to Thailand stock price is found in post-crisis. Meanwhile, in foreign exchange market across these two countries, the result shows unidirectional relationship from ringgit-bath to bath-ringgit at $10 \%$ significance level. The findings of causality relationship between stock price and exchange rate for Thailand and Malaysia within as well as across countries are summarized in Figure 5 and Figure 6.

\subsection{Variance decompositions (VDCS)}

The variance decomposition results are presented in Table 5 for pre-crisis and Table 6 for post-crisis, for five different accumulative months to 24 months.

Refer to the Table 5, through main diagonal, the extent to which a variable is exogenous explains most of its shock can be found; it then does not allow variances of other variables to contribute to it being explained. Obviously, in terms of the own shock being explained, Thailand stock price itself and secondly the Thailand exchange rate to a lesser degree illustrates its relative exogeneity with over $98.60 \%$ and $98.38 \%$ of own variances being explained by their own innovations. By far, the most explained variables in terms of its relative variance being explained by other variables, appears to be Malaysia exchange rate, where $95.55 \%$ of its shock are explained by innovations in other variables. In addition, results point to the Thailand stock price explaining a quite considerable proportion of fluctuations in the shocks to other variables.

VDCs which is useful in quantifying causal linkages is employed to examine the post-crisis analysis, which is presented in Table 6. Over post-crisis sample period, Thailand stock price and exchange rate still exogenous than Malaysia stock price and exchange rate. However, Thailand stock price seem to be even more exogenous in post-crisis than pre-crisis with $99.50 \%$ of its own variances being explained by its own innovations. While Thailand exchange rate seems less exogenous with over $97.01 \%$ of its shocks are accounted for by its innovations in post-crisis compare to pre-crisis. Besides that, we also found that Malaysia stock price in terms of its relative variance being explained by its own innovations increase from $80.69 \%$ in pre-crisis to $88.55 \%$ in post-crisis by $7.86 \%$ and Malaysia exchange rate, where $96.16 \%$ of its shocks are explained by innovations in other variables. The shock decreases by $0.39 \%$ in post-crisis compare to pre-crisis.

\section{Conclusion}

In this study, we examine the dynamic linkages between exchange rate and stock prices for Thailand and Malaysia. While literature suggests that the existence of significant interactions between the two markets, our empirical results show that stock prices Granger-cause exchange rates have more significant causal relationship compared with causal relationship from exchange rates to stock prices. This major finding is robust with respect to various statistical tests used, including the 
Johansen-Juselius cointegration test, the new Granger causality test, and a variance decomposition analysis. We develop a VAR model and use a multivariate MWald statistic to test restrictions on its parameters.

Based on the estimated results, we find that Granger causality is unidirectional causality relationship from stock prices to exchange either within country or across countries for the case of Thailand and Malaysia. In the case of Thailand, we found that Thailand is supportive of the portfolio approach, which suggest a unidirectional causal relationship from stock prices to exchange rates in pre-crisis and post-crisis. On the other hand, we also found Malaysia is supportive of the portfolio balance approach in post-crisis. There is interaction between the two stock markets in Malaysia and Thailand in pre-crisis. In the other word, the two markets are closely linked. There is only unidirectional causal relationship from Malaysia stock market to Thailand stock market in post-crisis. Our findings also suggest that there is bidirectional causal relationship between the foreign exchange for Thailand and Malaysia in post-crisis.

Furthermore, the findings show that there is unidirectional causal relationship from Malaysia stock market to Malaysia exchange rate, Thailand stock market, and Thailand exchange rate in post-crisis. Therefore, Malaysia can pursue policies to strengthen financial market transparency and accountability in the country that can prevent volatility in the stock prices as well as the erratic movement of the currency value in the foreign exchange market. This study only focuses on the linear relationships, thus, further study could be extended by using non-linear relationships between the variables.

\section{References}

Abdalla, I.S.A. \& Murinde, V. (1997). Exchange rate and stock price interaction in emerging financial markets: Evidence on India, Korea, Pakistan and the Philippines. Applied Financial Economics, 7, 25-35.

Aggarwal, R. (1981). Exchange rates and stock prices: a study of the United States capital markets under floating exchange rates. Akron Business and Economic Review, 21, 7-12.

Ajayi, R.A., Friedman, J. \& Mehdian, S.M. (1998). On the relationship between stock returns and exchange rates: Test of Granger causality. Global Finance Journal, 9 (2), 241-251.

Bahami-Oskooee, M. \& Sobrabian, A. (1992). Stock prices and the effective exchange rate of the dollar. Applied Economics, 24, 459-464.

Baharumshah, A. Z., Masih, A.M.M. \& Azali, M. (2002). The stock market and the ringgit exchange rate: a note. Japan and the World Economy, 14 (4), 471-486.

Canova, F. \& De Nicolo, G. (2000). Stock returns, term structure, inflation and real activity and inflation: An international perspective. Macroeconomic Dynamics, 4, 343-372

Dornbusch, R. \& S. Fischer, (1980). Exchange rates and current account. American Economic Review, 70, 960-971.

Edwards, S. (2002). Contagion. The World Economy, 23 (7), 873-900.

Granger, C. W.J., Huang, B.N. \& Yang, C.W. (2000). A bivariate causality between stock prices and exchange rates: Evidence from recent Asian flu. The Quarterly Review of Economics and Finance, 40, 337-354.

Gunduz, L. \& Hatemi-J, A. (2002). Stock price-volume relation in East European stock markets. Working Paper.

Hatemi-J, A. \& Irandoust, M. (2002). On the causality between exchange rates and stock prices: A note. Bulletin of Economic Research, 54 (2), 197-203.

Jang, H. \& Sul, Wonsil. (2002). The Asian financial crisis and the co-movement of Asian stock markets. Journal of Asian Economics, 13, 94-104.

Jenkinson, T. J. (1986). Testing neo-classical theories of labour demand: An application of cointegration techniques. Oxford Bulletin of Economics and Statistics, 48, 241-251.

Johansen, S. \& Juselius, K. (1990). Maximum likelihood estimation and inference of cointegration with application to the demand for money. Oxford Bulletin of Economics and Statistics, 52, 169-209.

Johansen, S. (1988). Statistical analysis of cointegration vectors. Journal of Economic Dynamics and Control, 12, 251-254.

Johansen, S. (1991), Estimation and hypothesis testing of cointegration vectors in Gaussian vector autoregression models. Econometrica, 59, 1551-1580.

Kaminsky, G., Lizondo, S. \& Reinhart, C. M. (1998). Leading indicators of currency Crises. IMF Staff Papers, 1-47.

Kasman, S. (2003). The relationship between exchange rates and stock prices: A causality analysis. Dokuz Eylöl Üniversitesi Sosyal Bilimler Enstitüsü Dergisi Cilt, 5 (2), 70-78.

Krueger, A.O. (1983). Exchange-Rate Determination. Cambridge University Press, Cambridge.

Ma, C. K. \& Kao, G. W. (1990). On exchange rate changes and stock price reactions. Journal of Business Finance \& Accounting, 17, 441-449. 
MacKinnon, J.G. (1996). Numerical distribution functions for unit root and cointegration tests. Journal of Applied Econometrics, 11, 601-618.

Masih, A.M.M. and Masih, R. (2002). Propagative causal price transmission among international stock markets: evidence from pre- and post-globalization period. Global Finance Journal, 13, 63-91.

Mishkin, F.S. (2000). Financial policies and the prevention of financial crises in emerging market economies. World Bank Policy Research Working Paper, No. 2683.

Mohamad, M. (2000). The Malaysian Currency Crisis: How and Why It Happened. Pelanduk Publication. Malaysia.

Muhammad, N. \& Rasheed, A. (2003). Stock prices and exchange rates: Are they related? Evidence from South Asian Countries? A paper presented at the 18th Annual General Meeting and Conference, Pakistan Society of Development Economists. Jan 13-15, 2003, Islamabad.

Nieh, C.C. \& Lee, C.F. (2001). Dynamic relationship between stock prices and exchange rates for G-7 countries. The Quarterly Review of Economics and Finance, 41, 477-490.

Pan, M.S., Fok, R.C.W. \& Liu, Y.A. (2001). Dynamic linkages exchange rates and stock prices: Evidence from Pacific Rim countries. Working Paper at College of Business Shippensburg University mimeo.

Rangvid, J. (2001). Increasing convergence among European stock markets? A recursive common stochastic trends analysis. Economic Letters, 71, 383-389.

Toda, H.Y. \& Yamamoto, T. (1995). Statistical inference in vector autoregressions with possibly integrated processes. Journal of Econometrics, 66, 225-250.

Wu, Y. (2001). Exchange rates, stock prices, and money markets: evidence from Singapore. Journal of Asian Economics, $12(3), 445-458$.

Table 1. Result of the Augmented Dickey-Fuller test $\left(\mathrm{H}_{0}\right.$ : unit root, $\mathrm{H}_{\mathrm{A}}$ : no unit root)

\begin{tabular}{lllll}
\hline & \multicolumn{3}{l}{ Levels } & \multicolumn{2}{l}{ First difference } \\
\cline { 2 - 5 } Variables & No trend & Trend & No trend & Trend \\
\hline \multicolumn{2}{l}{ Pre-crisis period $(1 / 11 / 1993$ to $31 / 5 / 1997)$} & & \\
SETI & $1.2292[1]$ & $-0.5668[1]$ & $-25.9169[0]^{* * *}$ & $-26.0526[0]^{* * *}$ \\
KLCI & $-2.7216[1]$ & $-2.9951[1]$ & $-20.5139[1]^{* * *}$ & $-20.5037[1]^{* * *}$ \\
THB/MYR & $-2.2556[15]$ & $-4.4102[15]^{* * *}$ & $-4.9362[14]^{* * *}$ & $-4.911214]^{* * *}$ \\
MYR/THB & $-2.2046[15]$ & $-4.4016[15]^{* * *}$ & $-5.0736[14]^{* * *}$ & $-5.0511[14]^{* * *}$ \\
Post-crisis period $(1 / 2 / 1998$ to & $31 / 8 / 2003)$ & & \\
SETI & $-2.4174[12]$ & $-2.4233[12]$ & $-10.3287[9]^{* * *}$ & $-10.4371[9]^{* * *}$ \\
KLCI & $-2.0233[20]$ & $-2.2394[20]$ & $-7.3033[19]^{* * *}$ & $-7.3133[19]^{* * *}$ \\
THB/MYR & $-2.0516[14]$ & $-3.2341[14]^{*}$ & $-8.1401[16]^{* * *}$ & $-8.1263[16]^{* * *}$ \\
MYR/THB & $-2.1099[14]$ & $-3.3486[14]^{*}$ & $-8.1283[16]^{* * *}$ & $-8.1168[16]^{* * *}$ \\
\hline
\end{tabular}

Note: $* * *, * * *$ denote significant at $10 \%, 5 \%$ and $1 \%$ significance levels, respectively.

Table 2. Results of the Phillips-Perron test $\left(\mathrm{H}_{0}\right.$ : unit root, $\mathrm{H}_{\mathrm{A}}$ : no unit root)

\begin{tabular}{lllll}
\hline & \multicolumn{3}{l}{ Levels } & \multicolumn{2}{l}{ First difference } \\
\cline { 2 - 5 } Variables & \multicolumn{1}{l}{ No trend } & Trend & No trend & Trend \\
\hline \multicolumn{2}{l}{ Pre-crisis period $(1 / 11 / 1993$ to $31 / 5 / 1997)$} & & \\
SETI & $1.4145[8]$ & $-0.5198[8]$ & $-25.9100[8]^{* * *}$ & $-25.9477[11]^{* * *}$ \\
KLCI & $-2.6055[6]^{*}$ & $-2.8474[5]$ & $-25.0486[11]^{* * *}$ & $-25.0336[12]^{* * *}$ \\
THB/MYR & $-1.6237[17]$ & $-3.0583[16]$ & $-25.9074[22]^{* * *}$ & $-25.8901[22]^{* * *}$ \\
MYR/THB & $-1.5810[16]$ & $-3.0801[15]$ & $-25.3183[22]^{* * *}$ & $-25.2980[22]^{* * *}$ \\
Post-crisis period $(1 / 2 / 1998$ to $31 / 8 / 2003)$ & & \\
SETI & $-2.1607[7]$ & $-2.1392[5]$ & $-34.5538[1]^{* * *}$ & $-34.7058[3]^{* * *}$ \\
KLCI & $-1.6356[5]$ & $-1.8096[5]$ & $-37.3855[3]^{* * *}$ & $-37.3756[3]^{* * *}$ \\
THB/MYR & $-1.9399[12]$ & $-3.1949[12]^{*}$ & $-34.6985[11]^{* * *}$ & $-34.7006[11]^{* * *}$ \\
MYR/THB & $-1.9723[11]$ & $-3.2633[10]^{*}$ & $-34.8430[10]^{* * *}$ & $-34.8493[10]^{* * *}$ \\
\hline
\end{tabular}

Note: $* * *, * * *$ denote significant at $10 \%, 5 \%$ and $1 \%$ significance levels, respectively. 
Table 3. Johansen and Juselius cointegration test

\begin{tabular}{|c|c|c|c|c|c|}
\hline \multirow{2}{*}{$\begin{array}{l}\lambda_{\text {trace }} \\
\mathrm{H}_{0}\end{array}$} & \multicolumn{5}{|c|}{$\lambda_{\max }$} \\
\hline & $\mathrm{H}_{\mathrm{A}}$ & t- statistic & $\mathrm{H}_{0}$ & $\mathrm{H}_{\mathrm{A}}$ & t- statistic \\
\hline \multicolumn{6}{|c|}{ Pre-crisis period (1/11/1993 to 31/5/1997) } \\
\hline $\mathrm{r}=0$ & $\mathrm{r} \geq 1$ & $95.5163 * * *$ & $\mathrm{r}=0$ & $\mathrm{r}=1$ & $79.2681 * * *$ \\
\hline $\mathrm{r} \leq 1$ & $r \geq 2$ & 16.2483 & $\mathrm{r} \leq 1$ & $\mathrm{r}=2$ & 10.6475 \\
\hline $\mathrm{r} \leq 2$ & $r=3$ & 5.6007 & $\mathrm{r} \leq 2$ & $\mathrm{r}=3$ & 4.2881 \\
\hline \multicolumn{6}{|c|}{ Post-crisis period (1/2/1998 to $31 / 8 / 2003)$} \\
\hline $\mathrm{r}=0$ & $\mathrm{r} \geq 1$ & $85.8733 * * *$ & $\mathrm{r}=0$ & $\mathrm{r}=1$ & $53.3935^{* * *}$ \\
\hline $\mathrm{r} \leq 1$ & $r \geq 2$ & $32.4798 * *$ & $\mathrm{r} \leq 1$ & $\mathrm{r}=2$ & 18.6578 \\
\hline $\mathrm{r} \leq 2$ & $\mathrm{r}=3$ & 13.8220 & $\mathrm{r} \leq 2$ & $\mathrm{r}=3$ & 8.8778 \\
\hline
\end{tabular}

Note: $* *$ and $* * *$ denote significant at $5 \%$ and $1 \%$ level.

Table 4. Test for Granger-causality applying the Toda-Yamamoto modified Wald test

\begin{tabular}{|c|c|c|c|c|}
\hline \multirow[b]{3}{*}{ Dependent variable } & \multicolumn{4}{|c|}{ Independent variable } \\
\hline & SETI & KLCI & THB/MYR & MYR/THB \\
\hline & \multicolumn{4}{|l|}{ F-statistic } \\
\hline \multicolumn{5}{|c|}{ Pre-crisis period (1/11/1993 to 31/5/1997) } \\
\hline SETI & - & $3.1623 * *$ & 1.2337 & 0.9510 \\
\hline KLCI & $4.5183 * * *$ & - & 1.5837 & 1.3761 \\
\hline THB/MYR & $2.4444^{*}$ & 1.7887 & - & $2.3983 *$ \\
\hline MYR/THB & $2.9900 * *$ & 1.5925 & 2.0101 & - \\
\hline \multicolumn{5}{|c|}{ Post-crisis period (1/2/1998 to $31 / 8 / 2003)$} \\
\hline SETI & - & $2.6142 * * *$ & 1.0879 & 0.8712 \\
\hline KLCI & 1.4282 & - & 0.8669 & 0.8203 \\
\hline THB/MYR & $2.9457 * * *$ & $2.0898 * *$ & - & $2.8471 * * *$ \\
\hline MYR/THB & $2.6118^{* * *}$ & $2.0923 * *$ & $2.4910^{* *}$ & - \\
\hline
\end{tabular}

Note: $*, * * * *$ denote significant at $10 \%, 5 \%$ and $1 \%$ significance levels, respectively. 
Table 5. Decomposition of variance for pre-crisis model

\begin{tabular}{|c|c|c|c|c|}
\hline \multirow[b]{2}{*}{ Days } & \multicolumn{4}{|c|}{ Percentage of forecast variance explained by innovations } \\
\hline & SETI & KLCI & THB/MYR & MYR/THB \\
\hline \multicolumn{5}{|c|}{ Relative variance in SETI } \\
\hline 1 & 100.0000 & 0.0000 & 0.0000 & 0.0000 \\
\hline 3 & 98.7207 & 0.6311 & 0.6370 & 0.0113 \\
\hline 6 & 98.6002 & 0.6668 & 0.7200 & 0.0130 \\
\hline 12 & 98.6001 & 0.6668 & 0.7200 & 0.0131 \\
\hline 24 & 98.6001 & 0.6668 & 0.7200 & 0.0131 \\
\hline \multicolumn{5}{|c|}{ Relative variance in $K L C I$} \\
\hline 1 & 17.2052 & 82.7948 & 0.0000 & 0.0000 \\
\hline 3 & 17.9190 & 80.8007 & 1.2416 & 0.0388 \\
\hline 6 & 17.8829 & 80.6914 & 1.3842 & 0.0415 \\
\hline 12 & 17.8829 & 80.6912 & 1.3842 & 0.0417 \\
\hline 24 & 17.8829 & 80.6912 & 1.3842 & 0.0417 \\
\hline \multicolumn{5}{|c|}{ Relative variance in $T H B / M Y R$} \\
\hline 1 & 0.1959 & 0.0235 & 99.7806 & 0.0000 \\
\hline 3 & 0.2903 & 0.7453 & 98.4194 & 0.5450 \\
\hline 6 & 0.2918 & 0.7515 & 98.3788 & 0.5779 \\
\hline 12 & 0.2918 & 0.7515 & 98.3771 & 0.5796 \\
\hline 24 & 0.2918 & 0.7515 & 98.3771 & 0.5796 \\
\hline \multicolumn{5}{|c|}{ Relative variance in $M Y R / T H B$} \\
\hline 1 & 0.1247 & 0.0065 & 96.8130 & 3.0558 \\
\hline 3 & 0.3066 & 0.7360 & 95.5546 & 3.4027 \\
\hline 6 & 0.3097 & 0.7437 & 95.4950 & 3.4516 \\
\hline 12 & 0.3097 & 0.7437 & 95.4936 & 3.4529 \\
\hline 24 & 0.3097 & 0.7437 & 95.4936 & 3.4529 \\
\hline
\end{tabular}

Notes: Figures in the first column refer to horizons (i.e. number of days) 
Table 6. Decomposition of variance for post-crisis model

\begin{tabular}{|c|c|c|c|c|}
\hline \multirow[b]{2}{*}{ Days } & \multicolumn{4}{|c|}{ Percentage of forecast variance explained by innovations } \\
\hline & SETI & KLCI & THB/MYR & MYR/THB \\
\hline \multicolumn{5}{|c|}{ Relative variance in SETI } \\
\hline 1 & 100.0000 & 0.0000 & 0.0000 & 0.0000 \\
\hline 3 & 99.5073 & 0.3163 & 0.0212 & 0.1553 \\
\hline 6 & 99.4995 & 0.3196 & 0.0220 & 0.1589 \\
\hline 12 & 99.4994 & 0.3196 & 0.0221 & 0.1589 \\
\hline 24 & 99.4994 & 0.3196 & 0.0221 & 0.1589 \\
\hline \multicolumn{5}{|c|}{ Relative variance in $K L C I$} \\
\hline 1 & 10.5371 & 89.4629 & 0.0000 & 0.0000 \\
\hline 3 & 10.7103 & 88.5639 & 0.6972 & 0.0286 \\
\hline 6 & 10.7103 & 88.5482 & 0.6983 & 0.0431 \\
\hline 12 & 10.7103 & 88.5479 & 0.6984 & 0.0434 \\
\hline 24 & 10.7103 & 88.5479 & 0.6984 & 0.0434 \\
\hline \multicolumn{5}{|c|}{ Relative variance in $T H B / M Y R$} \\
\hline 1 & 0.3645 & 1.0519 & 98.5837 & 0.0000 \\
\hline 3 & 1.6802 & 1.2113 & 97.0471 & 0.0614 \\
\hline 6 & 1.6840 & 1.2118 & 97.0130 & 0.0912 \\
\hline 12 & 1.6841 & 1.2118 & 97.0125 & 0.0917 \\
\hline 24 & 1.6841 & 1.2118 & 97.0125 & 0.0917 \\
\hline \multicolumn{5}{|c|}{ Relative variance in $M Y R / T H B$} \\
\hline 1 & 0.4062 & 0.9780 & 95.8239 & 2.7920 \\
\hline 3 & 1.5724 & 1.1203 & 93.6093 & 3.6980 \\
\hline 6 & 1.5808 & 1.1238 & 93.4533 & 3.8421 \\
\hline 12 & 1.5809 & 1.1238 & 93.4510 & 3.8443 \\
\hline 24 & 1.5809 & 1.1238 & 93.4510 & 3.8443 \\
\hline
\end{tabular}

Notes: Figures in the first column refer to horizons (i.e. number of days).

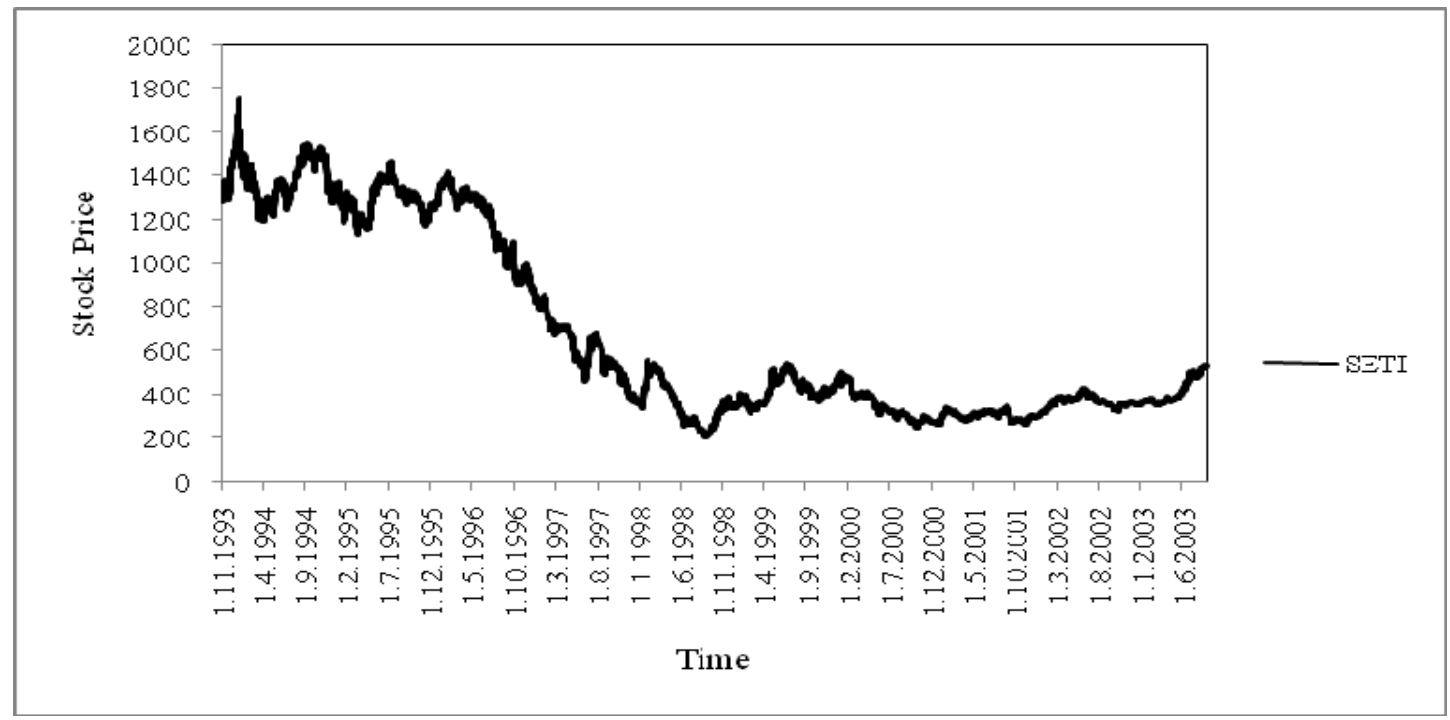

Figure 1. Thailand Stock Prices Fluctuations (Full Sample Period) 


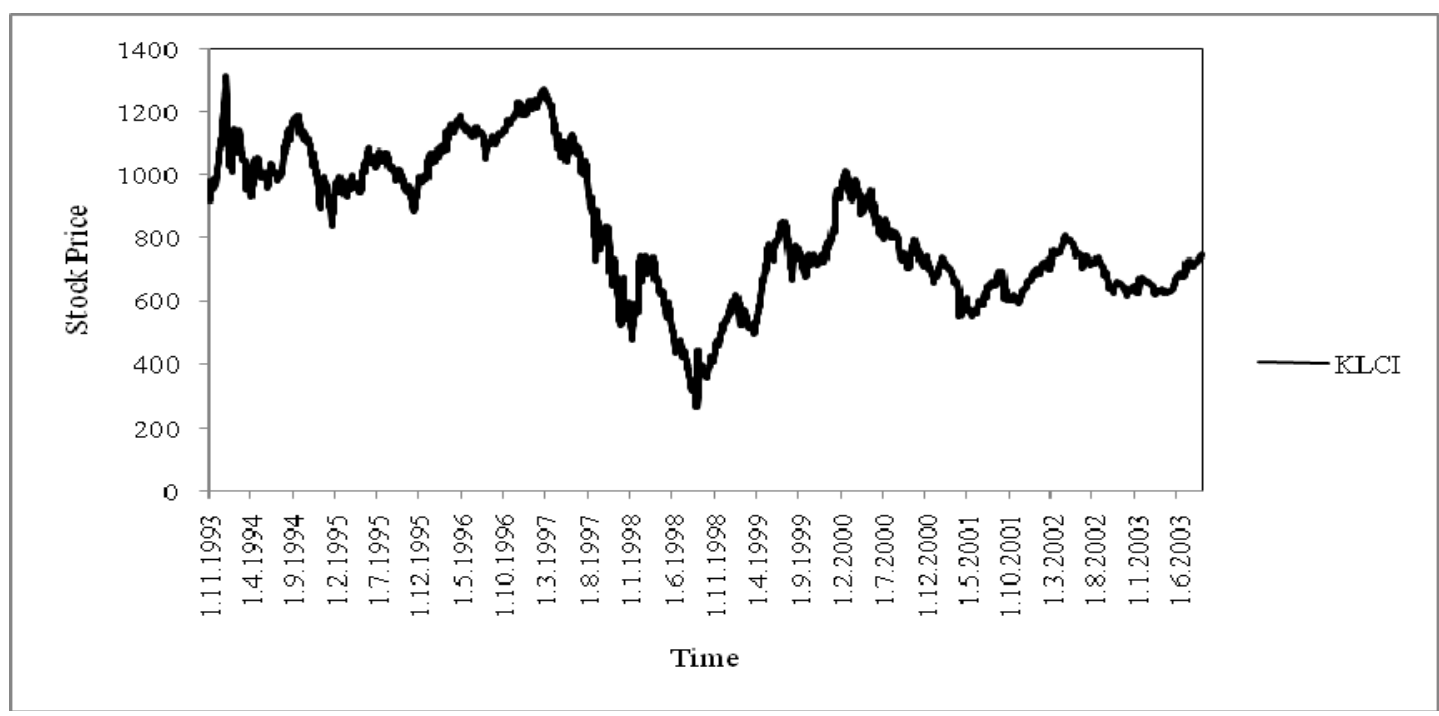

Figure 2. Malaysia Stock Prices Fluctuations (Full Sample Period)

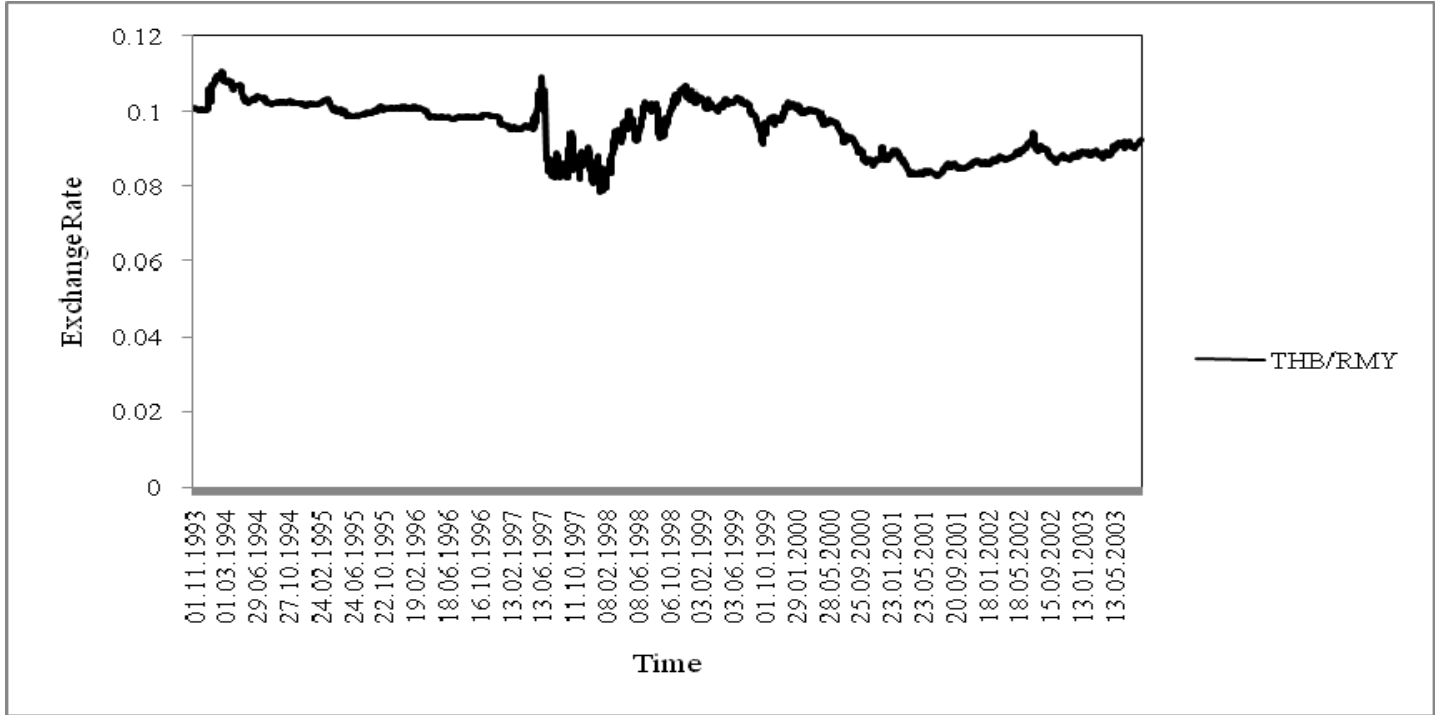

Figure 3. Thailand Exchange Rate Fluctuations (Full Sample Period)

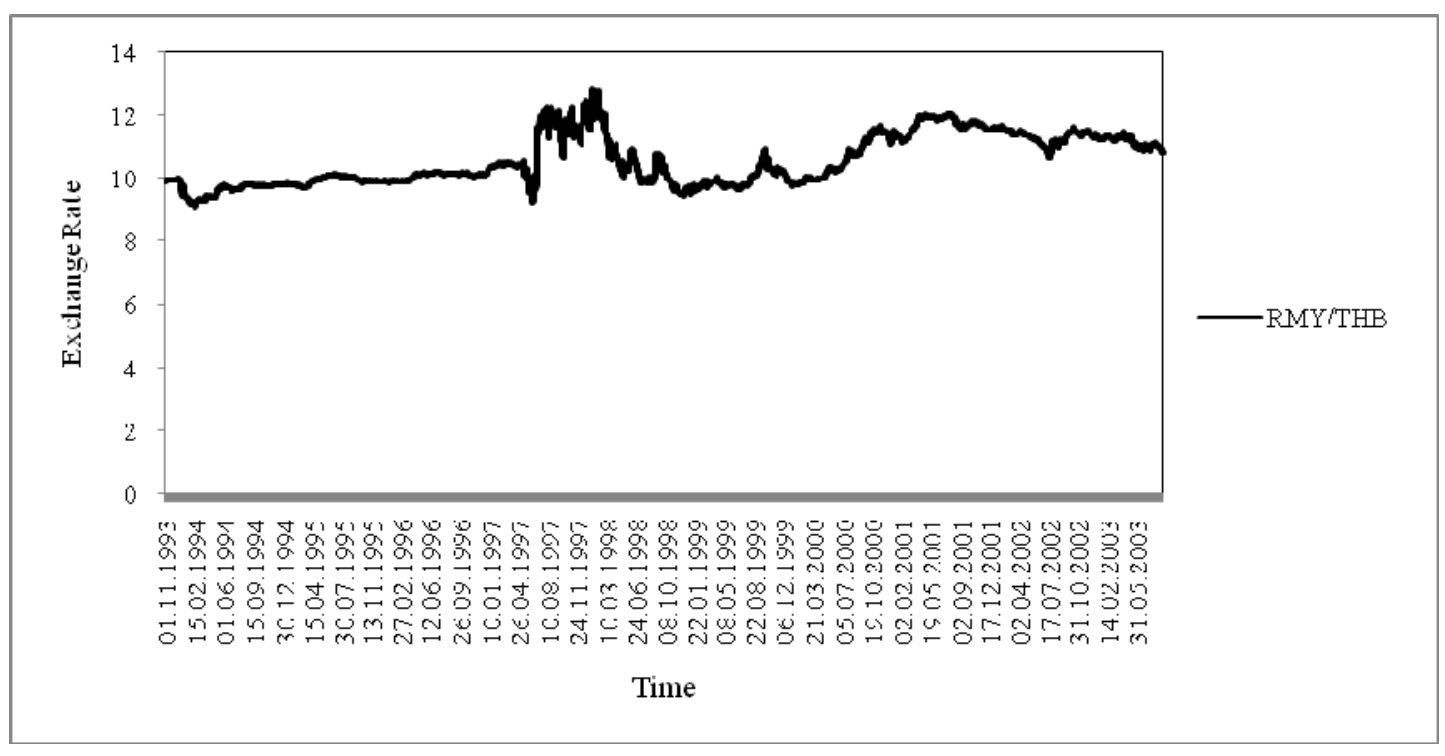

Figure 4. Malaysia Exchange Rate Fluctuations (Full Sample Period) 


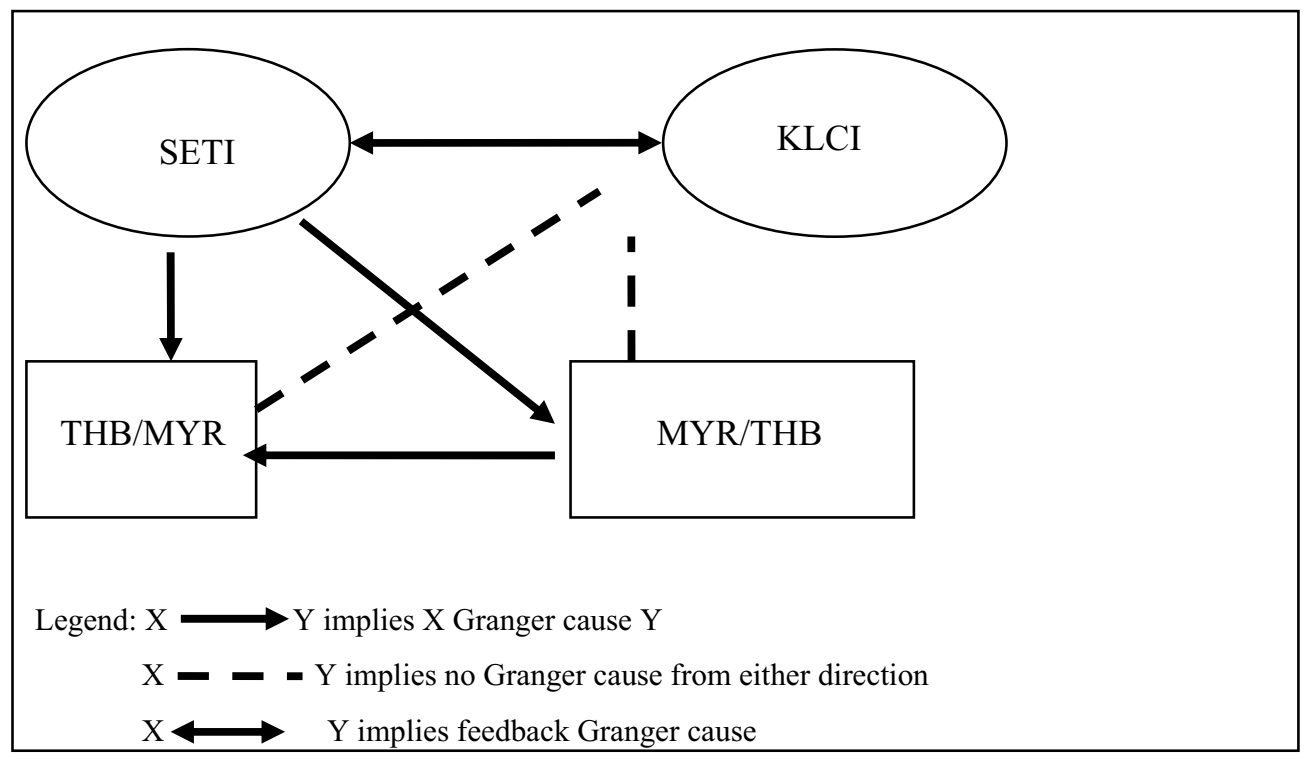

Figure 5. Summary of Granger-causality for pre-crisis

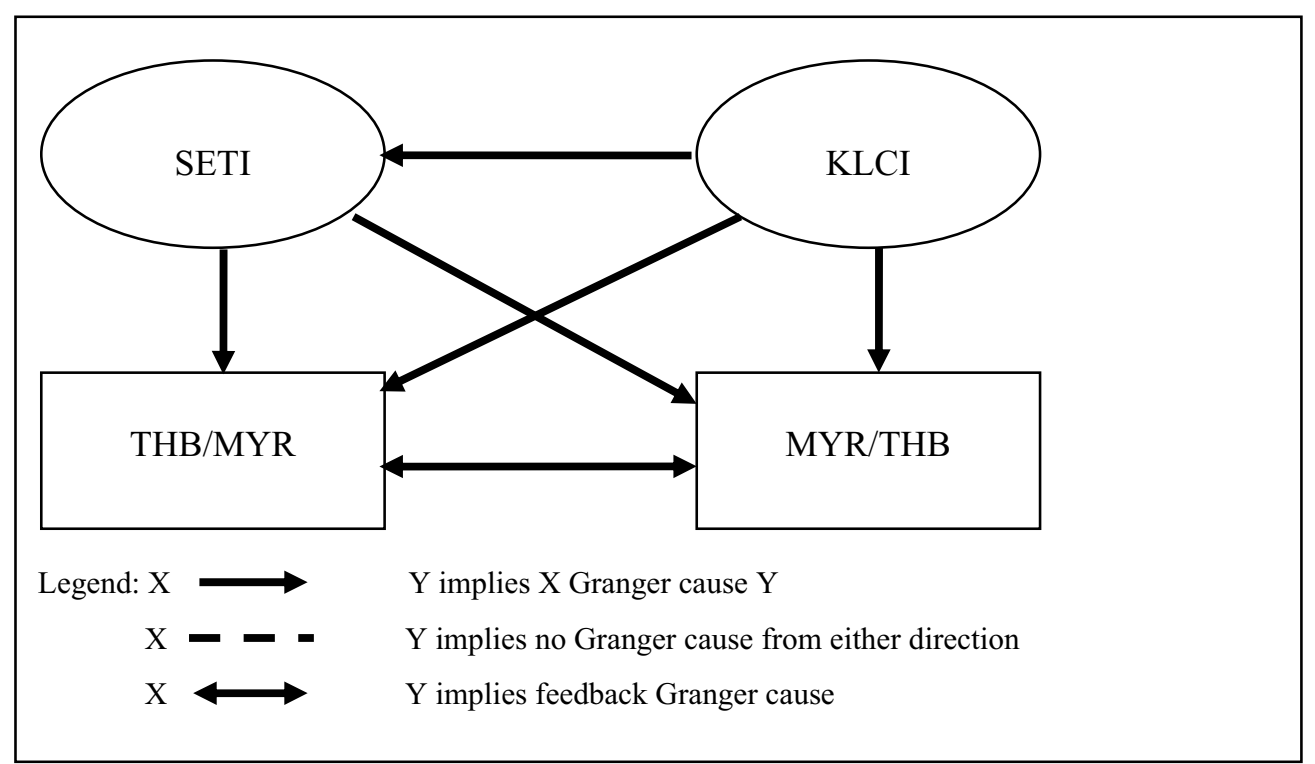

Figure 6. Summary of Granger-causality for post-crisis 